\title{
Resenha
}

\section{Monopólio revisado: a violência nos conflitos contra o Estado} Monopoly revised: violence in conflicts against the State http://dx.doi.org/10.5007/2178-4582.2017v51n2p500

Marcelo Borel Universidade do Estado do Rio de Janeiro, Rio de Janeiro/RJ, Brasil

Fernando Vieira de Freitas Universidade Federal do Rio de Janeiro, Rio de Janeiro/RJ, Brasil

\section{Resenha de:}

GELDERLOOS, P. Como a Não Violência protege o Estado. 1a. ed. Porto Alegre: Editora Deriva, 2011.

O livro escrito por Peter Gelderloos em 2007 e publicado no Brasil pela editora Deriva em 2011, tem como principal objetivo discutir as deficiências políticas e a insustentabilidade prática do projeto da não violência como instrumento de ação política. Essa empreitada se estende ao longo de seis capítulos nos quais o autor discute os motivos pelos quais a não violência é um método ineficaz, racista, estatista, patriarcal, estrategicamente inferior, e ilusório. Os pontos levantados e discutidos por Peter Gelderloos ao longo do livro podem ser condensados em dois grandes eixos argumentativos: um que trata a violência como um instrumento monopolizado pelo Estado e pelo homem branco; e outro que declara que ações não violentas não geram frutos capazes de alterar significativamente dinâmicas sociais.

O primeiro ponto cobre as acusações de que a não violência é estatista, racista e patriarcal. Nesse sentido, a opressão violenta promovida pelo estado sobre a sociedade civil, pelo patriarcado sobre as mulheres e transgêneros, e pelos brancos sobre os negros e outras minorias raciais, poderia ser legitimamente respondida através, também, do uso da violência como instrumento de ação política. A violência anti-opressão é vista por Gelderloos como uma maneira rápida e eficiente de desconstruir arranjos interacionais que fazem parte do modus operandi da sociedade contemporânea. Ela não é um fim, mas ponto de partida no qual se inicia um movimento gradativo de desconstrução dos sistemas de opressão. Nesse sentido, advogar que essas populações de- 
vam adotar uma postura comedida de não-violência, que busca a mudança unicamente através da política institucional, ou da calma paciente e resignada de que algum dia a mudança virá, é uma postura racista, patriarcal e estatista.

Já o segundo ponto remete aos capítulos nos quais o autor afirma ser a não violência ineficaz, estrategicamente inferior, e ilusória. Aqui, a argumentação do autor gira em torno do fato de que processos verdadeiramente revolucionários são invariavelmente violentos, de que as conquistas realizadas por movimentos violentos são sempre concomitantes à ação de movimentos violentos, e de que a não violência é incapaz de, sozinha, colocar em risco hegemonia e o poder do Estado.

A eficiência de métodos não violentos é reivindicada por seus ativistas graças às vitórias históricas que comumente lhe são atribuídas, cujos principais exemplos que podem lembrados são o processo de independência da Índia, liderado por Gandhi, e o movimento negro anti apartheid nos Estados Unidos, encabeçado por Martin Luther King Jr, passando pelos movimentos pacifista nos contextos das guerras do Vietnã e do Iraque. Contudo, segundo Peter Gelderloos, o sucesso da tática de resistência pacífica não pode ser atribuído unicamente a sua eficiência como instrumento de pressão política e econômica - ao contrário disso, seu sucesso deve-se, em grande parte, à coexistência de lutas violentas e armadas.

No caso da luta por direitos civis nos Estados Unidos essa coexistência é clara. Não se pode dar os louros do sucesso do movimento a Luther King deixando de lado a atuação dos Panteras Negras, personificado sobretudo na figura de Malcom X, que era apoiado por grande parte dos afro-americanos (p. 21). Na índia, por sua vez, mesmo que historicamente silenciada, a luta armada contra o colonialismo britânico contou com a atuação de importantes lideranças como Chandrasekhar Azad e Bhagat Singh. Soma-se a isso as baixas de contingente provocadas pela participação da Inglaterra nas duas grandes guerras mundiais. Ademais, segundo o autor, nenhum desses movimentos conseguiu atingir plenamente seus objetivos: ainda hoje se perpetua uma herança fortemente racista e segregacionista nos Estados Unidos, e o domínio colonial inglês sobre a Índia foi substituído por um neocolonial - crítica, contudo, que estende-se também à luta não pacífica.

Ao proclamar que a não violência é racista, Gelderloos argumenta sobre como a defesa exclusivista do "método pacifista", ainda que à primeira vista não pareça, está implicitamente inserida nas dinâmicas das desigualdades raciais e é, por esse motivo, uma postura que implica em privilégios. $\mathrm{O}$ autor procura demonstrar como historicamente os movimentos pacifistas ao redor do mundo condenaram manifestações ditas violentas praticadas por grupos et- 
nicamente recortados, e elogiaram a parcela não-violenta desses movimentos. Os exemplos levantados para corroborar esta hipótese são vários, mas o autor foca principalmente na clássica oposição entre o pacifismo de Martin Luther King Jr. e a postura de enfrentamento direto e autodefesa armada de Malcolm $\mathrm{X}$, dos Panteras Negras e do Exército e Libertação Negra, durante a luta por direitos civis nas décadas de 70 e 80 nos EUA.

O pacifismo branco erigiu como baluarte da resistência - aqui reduzida à ação não-violenta - personagens como Luther King Jr. e Gandhi, invés de diversas outras figuras que no mesmo momento realizavam seu combate. Um dos exemplos citados pelo autor é como a Marcha para Washington que marcou a luta pelos direitos civis nos Estados Unidos, foi associada, principalmente entre a elite branca pacifista, ao discurso I have a dream de Luther King Jr. Enquanto isso, permanece ausente da consciência branca - e tão influente quando a Marcha - a perspectiva crítica de Malcolm X.

A propagação da não violência, de acordo com o autor, é o que garante ao Estado o monopólio do uso da violência. Qualquer luta contra a repressão, afirma, precisa de um conflito com o Estado, de forma que a não violência faz um serviço ao Estado pacificando sua oposição sendo, portanto, estatista. $\mathrm{O}$ argumento pacifista toca na crença de que atos não violentos tendem a ser recebidos de forma igualmente pacífica pelo Estado, ao ponto que ações de cunho violento não apenas legitimam como também desencadeiam respostas igualmente violentas. Contudo, o Estado não é um ente estático ou meramente responsivo. Ao sentir a necessidade de reprimir um movimento, não precisa de razões prévias para fazê-lo: é capaz de criá-las forjando provas e implantando informantes nos movimentos populares. As manifestações ocorridas no Brasil em Julho de 2013 demonstram ambas as proposições de Gelderloos. Primeiramente, as ações violentas por parte da sociedade civil sugiram como uma resposta à brutalidade da ação policial contra as manifestações do Movimento Passe Livre (MPL) em São Paulo; em segundo lugar, ocorreram prisões arbitrária de manifestantes decorrentes de flagrantes forjados, sendo o caso mais emblemático o do morador de rua Rafael Braga - preso por portar um frasco de desinfetante.

A não violência é patriarcal. Sendo o patriarcado um sistema que se ampara sobretudo na violência masculina unilateral, tanto sobre as mulheres quanto sobre qualquer pessoa que não se encaixe nos sistemas binários homem/ mulher e masculino/feminino; negar o uso da violência a essas pessoas é ser conivente com o monopólio do uso da violência pelo homem - segue-se aqui a mesma linha de raciocínio utilizada na acusação de que a não violência é Estatal. A possibilidade de as vítimas do patriarcado - sobretudo as mulheres - lançarem mão da violência é "uma condição necessária para a libertação 
de gênero, assim como uma forma de empoderamento e de proteção no curto prazo" (p.91).

A violência é também frequentemente associada a um comportamento tipicamente masculino. Em contraponto, à mulher fica reservado o papel do diálogo, da passividade e, consequentemente, da não violência. A atribuição de papéis sociais e comportamentais a diferentes identidades de gênero é um dos grandes pilares sobre os quais se sustenta o patriarcado e que deve ser desconstruído. A reprodução da perspectiva de que a violência não cabe às mulheres não apenas reproduz e fortalece o patriarcado como ignora a partição histórica de mulheres em lutas por direitos e em processos revolucionários, como Juliete Paredes, Sylvia Rivera, Ann Hansen, Emma Goldman, Mollie Steimer, Anna Mae Pictou-Aquash, e os movimentos da Stonewall Rebelion (CAN), Mujeres Creando (BOL), Weather Underground (EUA), dentre outros. De acordo com o autor, quando perguntada se haveria alguma ligação entre o feminismo e a não violência, uma entrevistada respondeu que

\begin{abstract}
Há uma pressão substancial dentro do feminismo, que vincula as mulheres a não violência. Mas há um grande número de feministas lá fora, entre as quais eu mesma me incluo, que não querem se ver automaticamente incluídas em uma postura (isso é, a não violência), simplesmente por nossos órgãos genitais ou por nosso feminismo ${ }^{1}$.
\end{abstract}

A última acusação que Gelderloos faz é de que a não violência é um método ilusório. Para justificar essa afirmação, o autor mobiliza o argumento de que a não violência é sempre a saída mais fácil, uma vez que não incorre em riscos diretos para seus manifestantes, dado seu caráter intrinsecamente não revolucionário. Esse fato se desdobra nas outras duas críticas. Sendo uma saída mais fácil para os manifestantes, também facilita a repressão policial. O compromisso com o não enfrentamento permite que a ação policial para reprimir atos e prender manifestantes seja feita de forma tranquila, e por um contingente policial menor, diminuindo os custos - políticos, sociais e econômicos - da repressão, para o Estado. Por fim a não violência é ilusória por ser um método inerentemente não revolucionário. Como já foi dito, o Estado não precisa de ações violentas por parte da sociedade civil para respondê-la violentamente. O Estado não aceitaria passivamente as consequências de um processo reivindicatório que fosse capaz de colocar em xeque a estrutura e a organização estatal pelo simples fato de este não ser violento. A violência estatal para garantir sua perpetuação é um fato certo - independentemente

1 Retirado de "Feminism and nonviolence discussion", fev. e mar. 1998, disponível em $<$ https://networks.hnet.org/node/24029/pages/31316/feminism-and-non-violence-discussionfeb-and-march-1998>. Acessado em 20/10/2016. A referência é disponibilizada por Gelderloos no livro. 
dos métodos de ação utilizados pela sociedade civil em suas ações. Repousa nessa certeza a necessidade do uso da violência por qualquer organização que vise promover processos revolucionários de qualquer grau, ou implementar mudanças minimamente significativas no seio do Estado. A crença na não violência como forma de ação que estimula uma reformulação do Estado, em qualquer sentido, é, portanto, ilusória.

Seria então a violência a única maneira possível de agir politicamente de forma revolucionária e efetiva? Pode-se portanto resumir o livro de Peter Gelderloos a um elogio à violência? A resposta para essas duas perguntas é negativa. $\mathrm{O}$ propósito do autor ao tecer todas as críticas à não violência é apenas chamar a atenção para duas coisas: as limitações inerentes às táticas não violentas - enaltecendo a indispensabilidade da utilização de métodos híbridos nas lutas políticas -, e o caráter moral que envolve a condenação apriorística da violência, fazendo com que sua utilização seja muitas vezes negadas sem reflexão sobre as motivações pessoais e justificativas políticas que a sustentam. Além disso, o autor enfatiza também para o equívoco de se tratar a violência de forma fetichizada. Por mais que a ampliação da utilização de um repertório violento de ação deva passar inevitavelmente pela superação de um condicionamento cultural, não há porque situá-la em uma posição hierarquicamente superior aos demais métodos.

Desta forma, apesar de críticas elaboradas à utilização da não violência como arma central de formatar barganhas políticas com o Estado, Peter Gelderloos termina por reconhecer a viabilidade dessas táticas em determinados contextos, e a possibilidade de sua eficiência quando utilizada conjuntamente com formas mais radicais de ação. Contudo, essa posição final, de afabilidade com formas de ação não violentas, é apenas um pequeno lapso de comunhão teórica com pacifismo, que é, como demonstrado, criticado de forma veemente pelo autor ao longo de todo o seu livro.

\section{Referência}

GELDERLOOS, P. Como a Não Violência protege o Estado. 1a. ed. Porto Alegre: Editora Deriva, 2011. Disponível em: <https://kataklysma.noblogs.org/files/2016/02/Como-a -N $\%$ C3\%A3o-Viol \%C3\%Aancia-Protege-o-Estado-Peter-Gelderloos.pdf $>$. Acessado em: $20 / 10 / 2016$

Submissão em: 20/10/2016

Aceite em: 23/06/2017

Marcelo Borel é graduado em Ciências Sociais pela UFMG. Mestre em Ciência Política pela Unicamp. Atualmente é doutorando em Ciência Política no IESP/UERJ. Endereço para correspondência: Instituto de Estudos Sociais e Políticos da 
Universidade do Estado do Rio de Janeiro. R. da Matriz, 82. Botafogo. CEP 22260100 Rio de Janeiro/RJ, Brasil E-mail: marcelo.borel@gmail.com

Fernando Vieira de Freitas é graduado em Ciências Sociais pela UFMG. Mestre em Planejamento Urbano e Regional pelo IPPUR/UFRJ. Atualmente é doutorando em Antropologia Social no Museu Nacional/UFRJ.

E-mail: fernandosemba@gmail.com 